\title{
A two year retrospective study on outcome of forceps delivery - rejuvenating a dying art
}

\author{
Nina Philip*, Tapasya Dhar
}

Department of Obstetrics and Gynaecology, Christian Medical College, Ludhiana, Punjab, India

Received: 23 June 2016

Accepted: 12 July 2016

\section{*Correspondence:}

Dr. Nina Philip,

E-mail: ninalizphilip@yahoo.co.in

Copyright: $\odot$ the author(s), publisher and licensee Medip Academy. This is an open-access article distributed under the terms of the Creative Commons Attribution Non-Commercial License, which permits unrestricted non-commercial use, distribution, and reproduction in any medium, provided the original work is properly cited.

\section{ABSTRACT}

Background: The obstetric forceps was designed to assist the extraction of the fetal head and $10 \%$ of all deliveries in the western world are accomplished by either vacuum or forceps. Forceps helps in avoiding Caesarean sections and can help in reducing the increase in the number of Caesarean sections. The aim of the study was to evaluate the maternal and neonatal outcome in a tertiary care hospital over a period of two years.

Methods: This study was a retrospective observational study conducted over a period of two years from 1st July 2013 to 30th June 2015 in the labour ward of Christian Medical College and Hospital, Ludhiana. All operative vaginal deliveries conducted on singleton fetus in cephalic presentation were included in the study after applying the exclusion criteria. Maternal demographic data, various indicators for operative vaginal delivery and neonatal outcome were recorded.

Results: A total of 2920 deliveries took place in the study period of which 156 cases (5.34\%) were forceps delivery. The mean age of the patients was 26.2 years. The numbers of primigravida were 92 and multigravida was 64 . Low mid cavity and outlet forceps was applied in 67 and 89 patients respectively. The most common indication for application of forceps was fetal distress (56.4\%). Maternal morbidity was found in 36 women. Most of the babies were appropriate for gestational age (61.53\%). Only $10.25 \%$ of the babies had low APGAR score $<5$ and required NICU care.

Conclusions: The obstetric forceps is an effective instrument that may avoid unnecessary Caesarean sections and its complications.

Keywords: Forceps, Low midcavity, Outlet

\section{INTRODUCTION}

The obstetric forceps was designed to assist extraction of fetal head and thereby accomplish the delivery of the fetus. Approximately $10 \%$ of all deliveries in western world are accomplished by one of the two methods of operative vaginal birth, vacuum or forceps. ${ }^{1}$

However potential maternal complications including severe perineal lacerations make the use of forceps controversial. $^{2}$
Forceps which was initially introduced by Chamberlain has undergone many modifications to its present form. This instrument has helped in avoiding numerous Caesarean sections. In the present day when there is a universal concern regarding the alarming rise of Caesarean section rates, a better understanding of outcome of mother and neonate will help to remove the prejudice against the instrument.

The aim of the present study was to evaluate the maternal and neonatal outcome in a tertiary care hospital over a period of two years. 


\section{METHODS}

This study was a retrospective observational study conducted over a period of two years from $1^{\text {st }}$ July 2013 to $30^{\text {th }}$ June 2015 in the labour ward of Christian Medical College and Hospital, Ludhiana.

\section{Inclusion criteria}

All operative vaginal deliveries conducted on singleton fetus in cephalic presentation were included in the study. All deliveries were performed by experienced obstetricians and by residents under the supervision of an attending consultant.

\section{Exclusion criteria}

- Multiple pregnancy

- Still births

- Estimated fetal weight less than $2 \mathrm{~kg}$ or more than 4 $\mathrm{kg}$

- Fetal anomalies

- Non cephalic presentation

Maternal demographic data such as maternal age, parity, gestational age at delivery and birth weight, indication of forceps delivery, rate of induction of labour were noted. Prolonged second stage of labour (inadequate progress for 2 hours in primigravida and 1 hour in multipara with documented uterine activity) and maternal exhaustion (maternal inability to deliver due to physical exhaustion) were considered as indications of operative vaginal delivery. Furthermore, non-reassuring fetal heart such as tachycardia, bradycardia and late deceleration of fetal heart and other reason like previous caesarean section and maternal co-morbidity (cardiac disease, pre-eclampsia, anaemia) were included in indicators for operative vaginal delivery. Neonatal outcome with respect to baby weight, APGAR and admission to neonatal intensive care unit were recorded.

\section{RESULTS}

Table 1: Indications of forceps application.

\begin{tabular}{|c|c|c|}
\hline Indication & Number $(n=156)$ & $\%$ \\
\hline Fetal distress & 88 & 56.41 \\
\hline Poor maternal efforts & 33 & 21.16 \\
\hline $\begin{array}{l}\text { Prolonged second } \\
\text { stage }\end{array}$ & 14 & 8.97 \\
\hline Medical comorbidity & 21 & 13.46 \\
\hline
\end{tabular}

A total of 2920 deliveries took place in the study period of which 156 cases $(5.34 \%)$ were of instrumental delivery (forceps). The mean age of the patients was 26.2 years. The number of primigravida was 92 and multigravida was 64. Low mid cavity forceps and outlet forceps were applied in 67 and 89 patients respectively.
The most common indication for application of forceps was fetal distress $(56.4 \%)$ followed by poor maternal efforts $(21.15 \%)$ (Table 1$)$.

Table 2: Maternal injuries.

\begin{tabular}{|lll|}
\hline Injuries & Number n=156 & $\%$ \\
\hline $\begin{array}{l}\text { Complete perineal } \\
\text { laceration }\end{array}$ & 4 & 2.56 \\
\hline $\begin{array}{l}\text { Laceration of vagina } \\
\text { or cervix }\end{array}$ & 13 & 8.33 \\
\hline $\begin{array}{l}\text { Episiotomy extensions } \\
\text { or hematoma }\end{array}$ & 14 & 8.97 \\
\hline Atonic PPH & 5 & 3.21 \\
\hline
\end{tabular}

The maternal morbidity associated with forceps was found in 36 women $(23.07 \%)$. There were 14 women who had episiotomy extension, 13 patients had vaginal and/or cervical lacerations and 4 patients had complete perineal tears. Postpartum haemorrhage occurred in 5 cases, all being atonic. Maternal injuries are given in Table 2. The complete perineal tears were in women with large for gestational age babies.

Table 3 shows that mostly appropriate for age babies were born $(61.53 \%)$ and only $28.2 \%$ were small for gestational age.

Table 3: Baby weight.

\begin{tabular}{|lll|}
\hline Weight & Number & $\%$ \\
\hline$\leq 2.5 \mathrm{~kg}$ & 44 & 28.2 \\
\hline $2.5-3.5 \mathrm{~kg}$ & 96 & 61.5 \\
\hline$\geq 3.5 \mathrm{~kg}$ & 16 & 10.3 \\
\hline
\end{tabular}

Regarding the neonatal outcome 16 babies (10.25\%) had low Apgar score $<5$ and required NICU care. There were 2 neonatal deaths in our study which were due to fetal distress and meconium stained amniotic fluid.

\section{DISCUSSION}

This study was performed to estimate the short term maternal and neonatal morbidity in association with forceps delivery. The rate of instrumental delivery in our study was $5.34 \%$ which was comparable to previously published studies. ${ }^{3,4}$

The most frequent indication for forceps was fetal distress $(56.41 \%)$ followed by poor a maternal effort $(25.15 \%)$ which was similar to a study by John et al and Yeomans ER. ${ }^{4,6}$ In another Indian study, cutting short second stage of labour (i.e. where prolonged bearing down is detrimental to the mother in cases of maternal co-morbidity) was the chief indication followed by prolonged second stage. ${ }^{7}$ In another study the chief indication was prolonged second stage. ${ }^{3}$ 
Regarding maternal morbidity there were a total of 31 $(19.86 \%)$ cases having injuries. The minor cervical and vaginal lacerations were easily managed with a few extra sutures during episiotomy repair. The rate of maternal injuries was $12.5 \%$ in a study by John et al. ${ }^{5}$

The risk factors for complete perineal tears as in other studies were the same. In our study, out of the 4 cases of complete perineal tears, 3 were primigravida with large for gestational age babies and all had a right mediolateral episiotomy. The fourth patient had preterm baby and was a multigravida. Complete perineal tears may occur in deliveries when baby weight is more, short perineum, poor perineal support or sudden extension of the head. Proper hemostasis, careful suturing with liquid diet for 24 hours and low residue diet with a stool softener for 3- 4 days is the management. ${ }^{8}$

Regarding the perinatal outcome 16 babies $(10.25 \%)$ had low APGAR scores requiring NICU admissions and 11 were handed over to the mother in 48 hours. There were two neonatal deaths which were due to MSAF in one and fetal distress in the other. Forceps were applied in fetal distress because shifting to operation theatre would have led to delay in delivery. In a study by Prapas et al interestingly Apgar score $\leq 4$ at 1 minute was more commonly seen after forceps delivery and duration of NICU stay was also longer after forceps delivery. ${ }^{3}$

\section{CONCLUSION}

The obstetric forceps is an effective instrument that may avoid unnecessary Caesarean sections and its complications. However appropriate training is required before forceps application. The use of forceps should be rejuvenated so that proper skills to perform forceps delivery in a competent manner are imparted. It is important that the art of forceps is not lost to future generation of obstetricians and the women they care for.
Funding: No funding sources Conflict of interest: None declared

Ethical approval: The study was approved by the Institutional Ethics Committee

\section{REFERENCES}

1. Wen SW, Liu S, Kramer MS, Ohlsson A, Sauve R, Liston R. Comparison of maternal and infant outcomes between vacuum extraction and forceps deliveries. Am J Epidemiol. 2001;153:103-7.

2. Miller ES, Barber EL, McDonald KD, Gossett DR. Association between obstetrician forceps volume and maternal and neonatal outcomes. Obstet Anaesthesia Digest, 2015.

3. Prapas N, Kalogiannidis I, Masoura S, Diamanti E, Makedos A, Drossou D, et al. Operative vaginal delivery in singleton term pregnancies: Short-term maternal and neonatal outcomes. Hippokratia. 2009; $12: 41-5$.

4. Lurie S, Glezerman M, Sadan O. Maternal and neonatal effects of forceps versus vacuum operative vaginal delivery. Int $\mathrm{J}$ Gynecol Obstet. 2005;358:1203-7.

5. John LB, Nischintha S, Ghose S. Outcome of forceps delivery in a teaching hospitals two year experience. Journal of Natural Science, Biology and Medicine. 2014;155-7.

6. Yeomans ER. Operative vaginal delivery. Obstet Gynecol. 2010;115:645-53.

7. Singh A, Rathore P. A comparative study of Fetomaternal outcome in instrumental vaginal delivery. $\mathrm{J}$ Obstet Gynaecol India. 2011;61:663-6.

8. Talukdar S, Purandare N, Coulter-Smith S, Geary M. Is it time to rejuvenate the forceps? J Obstet Gynaecol India. 2013;63:218-22.

Cite this article as: Philip N, Dhar T. A two year retrospective study on outcome of forceps delivery rejuvenating a dying art. Int J Reprod Contracept Obstet Gynecol 2016;5:2810-2. 